\title{
Perceptions of Tenure and Promotion Guidelines and Criteria Among Athletic Training Doctoral Students
}

\author{
Stephanie M. Mazerolle \\ University of Connecticut, Storrs, stephanie.m.singe@uconn.edu \\ Thomas Bowman \\ Lynchburg College, bowman.t@lynchburg.edu \\ Joanne Klossner \\ University of Maryland, jklossne@umd.edu
}

Follow this and additional works at: https://nsuworks.nova.edu/ijahsp

Part of the Medicine and Health Sciences Commons

This Manuscript has supplementary content. View the full record on NSUWorks here: https://nsuworks.nova.edu/ijahsp/vol15/iss3/5

\section{Recommended Citation}

Mazerolle SM, Bowman T, Klossner J. Perceptions of Tenure and Promotion Guidelines and Criteria Among Athletic Training Doctoral Students. The Internet Journal of Allied Health Sciences and Practice. 2017 Jan 01;15(3), Article 5.

This Manuscript is brought to you for free and open access by the College of Health Care Sciences at NSUWorks. It has been accepted for inclusion in Internet Journal of Allied Health Sciences and Practice by an authorized editor of NSUWorks. For more information, please contact nsuworks@nova.edu. 


\title{
Perceptions of Tenure and Promotion Guidelines and Criteria Among Athletic Training Doctoral Students
}

\begin{abstract}
Purpose: Evidence suggested that athletic training doctoral candidates are being socialized through a variety of formal and informal experiences to prepare them for roles in higher education. It is unclear, however, if they are aware of the expectations associated with tenure and/or promotion which are necessary for transition into higher education. Perceptions of tenure and promotion among doctoral students preparing to enter the athletic training professoriate were investigated. Methods: Twenty-four students $(16=$ females, $8=$ males, average age $=28 \pm 3$ years) completed one-on-one telephone interviews. Data were analyzed using a general inductive approach, with a peer review and multiple analyst triangulation completed for rigor. Results: Four primary themes emerged from the data: 1) there is a limited understanding of the guidelines and criteria for tenure and promotion, 2) knowledge of guidelines and criteria is perpetuated by mentoring, 3 ) research/scholarship is perceived as paramount for success, and 4) the belief that skills gained, regardless of the domain of tenure, can facilitate success in others. Conclusions: The findings suggest that doctoral students in athletic training are partially aware of the guidelines for tenure, but could benefit from additional mentoring.
\end{abstract}

\section{Author Bio(s)}

Stephanie M. Mazerolle, PhD, ATC, FNATA is an assistant professor of Athletic Training in the Department of Kinesiology at the University of Connecticut. She directs the Professional Athletic Training program. Her research focus is centered on professional and organizational socialization.

Thomas G. Bowman, PhD, ATC is an associate professor at Lynchburg College, teaching in the Athletic Training Program. A certified athletic trainer, Dr. Bowman's research is focused on the socialization processes for athletic trainers in a variety of roles.

Joanne Klossner, PhD, ATC is an adjunct faculty member at the University of Maryland. Her research has focused on development of role understanding through professional interactions. 


\title{
TUAHSP \\ The Internet Joưnal of Allied Health Sciences and Practice \\ Dedicated to allied health professional practice and education \\ Vol. 15 No. 3 ISSN 1540-580X \\ Perceptions of Tenure and Promotion Guidelines and Criteria Among Athletic Training Doctoral Students
}

\author{
Stephanie M. Mazerolle, PhD, ATC, FNATA ${ }^{1}$ \\ Thomas Bowman, PhD, ATC 2 \\ Joanne Klossner, PhD, ATC ${ }^{3}$ \\ 1. University of Connecticut \\ 2. Lynchburg College \\ 3. University of Maryland \\ United States
}

\begin{abstract}
Purpose: Evidence suggested that athletic training doctoral candidates are being socialized through a variety of formal and informal experiences to prepare them for roles in higher education. It is unclear, however, if they are aware of the expectations associated with tenure and/or promotion which are necessary for transition into higher education. Perceptions of tenure and promotion among doctoral students preparing to enter the athletic training professoriate were investigated. Methods: Twentyfour students $(16=$ females, $8=$ males, average age $=28 \pm 3$ years) completed one-on-one telephone interviews. Data were analyzed using a general inductive approach, with a peer review and multiple analyst triangulation completed for rigor. Results: Four primary themes emerged from the data: 1) there is a limited understanding of the guidelines and criteria for tenure and promotion, 2) knowledge of guidelines and criteria is perpetuated by mentoring, 3) research/scholarship is perceived as paramount for success, and 4) the belief that skills gained, regardless of the domain of tenure, can facilitate success in others. Conclusions: The findings suggest that doctoral students in athletic training are partially aware of the guidelines for tenure, but could benefit from additional mentoring.
\end{abstract}

\section{INTRODUCTION}

Academic tenure is a system adopted by many universities and colleges as a means to help provide academic freedom to faculty as well as, to a certain degree, job security. ${ }^{1}$ Achieving tenure is through the tenure-earning position in which faculty members have a period of time to meet the criteria of their institutions' pre-determined criteria. The criteria for granting tenure, promotion, or permanent status is often evaluated within three broad categories of academic engagement and include: 1) teaching, 2) research, and 3) service. ${ }^{1}$ Each broad category is weighted according to the values of the particular institution and/or department or college. However, emphasis is often placed on research publications, grant attainment, success as an educator, and public and community engagement.

Tenure is a long-standing tradition among institutions of higher education but it can be viewed as a challenge for those faculty members in health-related fields, including athletic training. ${ }^{2,3}$ Beyond the typical three areas of tenure, athletic training faculty members, like other peer healthcare faculty, have to balance administrative duties associated with programmatic tasks and accreditation standards. ${ }^{3}$ Moreover, the fundamental aspect of healthcare fields is the clinical aspect of the educational process, which requires faculty members to remain clinically competent. Juggling these roles, in addition to meeting the other areas noted for success, is critical for the athletic training faculty members' tenure pursuit, yet can create challenges and additional stress. The transition into higher education can be innately stressful, even despite doctoral education, which is aimed at providing awareness of the expectations, climate, culture, and tenure process. ${ }^{4}$ 
As the athletic training profession transitions to a graduate model for education more qualified and doctorally trained educators will be necessary. ${ }^{5}$ With this increase in demand, it is important to ensure that those who embark on the process to become a faculty member through doctoral education are fully prepared to handle the responsibilities that will be expected of them. ${ }^{6}$ Role occupation is often one way doctoral students can gain awareness to the roles and responsibilities associated with higher education. Role occupation speaks to the opportunities provided to doctoral students that allow them to engage in activities that orientate and acclimate them to the culture of higher education. However, recent evidence suggests that these experiences are heavily dominated by research and teaching skill development, with less emphasis on other aspects such as service and administrative tasks. ${ }^{7-9}$ The field of athletic training is unique, as faculty members serving in this role must also balance accreditation and administrative tasks that embody the degree program on top of the traditional tenure earning expectations. As recently pointed out, the role of the athletic training educator is complex and simple completion of a doctoral degree or experiences teaching may not fully capture the role of the professoriate. ${ }^{5}$ This suggests that the profession and those who are preparing future faculty must provide a breadth of experiences to help the athletic trainer and doctoral candidate transition into this role.

Research is often the foundation to doctoral education, as this aspect of higher education is often weighted as instrumental in earning tenure, as well as maintaining and advancing the research base of the university. $2,10,11$ Therefore, it is not surprising that scholarly development and productivity is a major aspect of the doctoral experience in athletic training. ${ }^{6}$ However, it is evident that doctoral education within athletic training is not as robust compared to other areas of higher education, as chances for engaging in service and administrative duties are limited. ${ }^{7}$ This is critical from a role inductance and transition to practice standpoint, as a comprehensive doctoral education experience can facilitate a smoother transition into higher education. Fundamentally speaking, knowledge and experience can be powerful as it can prepare new faculty members to be ready for their new role and the expectations that accompany that role.

The socialization process is often the platform whereby individuals learn about these responsibilities that will shape their future role. 12,13 Mentoring received is a large part of this process, as the mentor serves as a nexus to role understanding. ${ }^{8}$ The relationship between mentor and mentee is critical, as it allows future faculty members more awareness of what is to come. This awareness may facilitate success during the transition to academia. Understanding future faculty members' appreciation of tenure is necessary as the profession grows and transitions to a graduate level model. Those who mentor these future faculty members may have gained their tenure and exposure to the criteria through expectations that focused more on the clinical and didactic aspects of promotion, and less on the research and service pieces now widely expected in most institutions. ${ }^{3}$ Moreover, although students are being awarded doctoral degrees, they may not gain employment at comparable institutions to where they earned their terminal degree (i.e. expectations for tenure vary based upon Carnegie classification), thus expectations for tenure and promotion can be convoluted. ${ }^{14}$

Doctoral students are the future of the profession and doctoral education should provide the platform for successful transition into the faculty member role. However, little is known about students' understanding of the criteria used to evaluate success as an academician. Some faculty do not successfully navigate the tenure process in athletic training potentially due to competing expectations or a lack of awareness of expectations of their institution. ${ }^{3}$ The purpose of this study was to determine the general knowledge base and perceptions of athletic training doctoral students concerning tenure (PTR) guidelines and criteria. Ascertaining this can help train future faculty as a means to not only provide successful transition into their role, but also to help them remain professionally committed and productive.

\section{METHODS}

\section{Research Design}

An exploratory, qualitative paradigm was used to investigate participants' perceptions on the tenure and promotion process in higher education. This method allowed exploration of the experiences of the participants' as little is known about this particular subgroup within athletic training. The semi-structured nature allowed for discourse between the interviewer and interviewee as a means to provide rich data. ${ }^{15}$ Furthermore, when using the socialization framework for research, exploratory design is commonplace.

\section{Participants}

A purposefully recruited 28 doctoral students (19 females, 9 males) followed a criterion sampling procedure.$^{16}$ Athletic trainers were recruited who were employed through graduate assistantships as they navigated their doctoral degree programs. Because of the concerned perceptions of the PTR process, participants were screened regarding their career plans post-graduation. Twenty-four participants responded they would like to pursue a faculty position upon finishing their doctoral degree (Table 1). Thus, their data were utilized only for this portion of the study. The remaining participants $(n=4)$, were part of a larger study

(c) The Internet Journal of Allied Health Sciences and Practice, 2017 
examining doctoral education in athletic training. ${ }^{7-9}$ For those seeking a career in the professoriate, nine specifically stated they would pursue a teaching focused position, seven would like the majority of their responsibilities to be spent on research, four desired a split appointment between teaching and clinical practice as an athletic trainer, two were undecided on an exact position type, and two wanted to have administrative roles in addition to other faculty responsibilities such as a program coordinator.

The average age of the 24 participants was $28 \pm 3$ years. The participants represented nine different higher education institutions, with the majority of them $(n=19)$ completing their doctoral education at R1 universities as classified by the Carnegie Classification. ${ }^{17}$ The others $(n=5)$ were at R2 universities. The athletic trainers had been certified practitioners for $6 \pm 3$ years. Most participants had teaching $(\mathrm{N}=8)$ or research $(\mathrm{N}=9)$ assistantships that funded their doctoral education experiences. Others $(\mathrm{N}=5)$ reported a split between teaching and research, while 2 were funded by clinical responsibilities (i.e. medical care provided to local universities, high schools, etc.) and one received funding by completing administrative tasks associated with program administration/maintenance.

\section{Data Collection Procedures}

Semi-structured, one-on-one interviews with all of the participants were completed after securing institutional review board approval. Each interview session lasted 45 to 60 minutes and, upon completion, was transcribed verbatim. The interview sessions followed a structured interview guide, as a means to establish flow and consistency between interviews but also allowed for some unplanned discourse between the researchers and participants. The interview guide was drafted to reflect the purpose and the socialization literature that founded the larger study.7,-9,12,13,18 A peer reviewed the interview guide before the study was piloted. The pilot study was completed with one doctoral student meeting the inclusion criteria. For the purposes of this paper, attention was focused on the questions and data generated from discussions of their knowledge of the tenure process. The first question asked, "Most institutions of higher education evaluate faculty on their contributions through various review processes: What is your understanding of such processes and the areas of contribution upon which faculty are typically evaluated?" Questions were followed up regarding "criteria believed to be critical in tenure," and their "level of satisfaction towards their readiness to pursue tenure." These questions were used as the primary data for analyses.

\section{Data Analysis and Credibility}

The data were analyzed using a general inductive approach. ${ }^{19}$ The process included evaluating the data with a holistic lens through several "reads" of the transcripts. This attained a sense of the participants' experiences and perceptions. Then, as the meaningful pieces of data began to emerge, labels were drafted in the margins of the transcripts. Those labels were representative of the overall meaning. Then the labels were collapsed into categories as a means to provide a description of the data. This process continued until only the emergent themes as it pertained to the research agenda remained.

Peer review and researcher triangulation were selected as means to establish data rigor and trustworthiness. Both methods are commonplace in qualitative research design and provide triangulation between the data collected and interpreted by the researchers. ${ }^{16}$ The peer reviewer was a qualitative researcher with previous experience in socialization literature and qualitative research. The peer analyzed the methodology and interview guide, and reviewed the data to confirm the findings. Analyses were completed by two researchers, independently as a means to maintain rigor and to reduce researcher bias during the general inductive analysis.

\section{RESULTS}

Four primary themes emerged from the data (Figure 1): 1) there is a limited understanding of the guidelines and criteria for tenure and promotion, 2) knowledge of guidelines and criteria is perpetuated by mentoring, 3) research/scholarship is perceived as paramount for success, and 4) belief that skills gained, regardless of the domain of tenure, can facilitate success in others. Data are provided to support the analysis by sharing quotes from the interviews. Each participant is identified with an assigned name.

\section{Limited understanding of the guidelines and criteria for tenure and promotion}

The participants indicated they had a very limited knowledge about tenure guidelines and criteria. During the interview sessions, participants were asked to describe their knowledge and perceptions of the criteria used to evaluate faculty. Mary said, "I wouldn't say like a great understanding "when asked to describe the tenure process. Jessica had a similar response about her knowledge of tenure and promotion, saying, "I guess only the fact that they're - I don't know - honestly, I don't know within each of those (three areas), how they're evaluated." Robyn shared that her knowledge was "Limited." When asked to explain, she continued,

II'm not familiar really at all. I mean, I'm familiar with the components and kind of more along the lines of getting onto a tenure track, but I don't really know expectations depending on your level, your role at the

(ㄷ The Internet Journal of Allied Health Sciences and Practice, 2017 
university. I'm still not - I couldn't explain it to somebody I guess I should say."

Isabella when asked about her understanding of the tenure and promotion guidelines shared,

"Oh I am not sure on specifics. I'm not sure how they do it like at [my current school]. I know we have student evaluations. And tenure, it was based on communication and leadership. And I think there is some sort of, with the faculty, a research component. I don't know if that is helpful - that answered the question?"

Participants discussed not having the chance to gain exposure to the process of faculty assessment and the criteria used to evaluate performance. John, a third year doctoral student, discussed that at this stage in his studies, he had very limited opportunity to learn about the process. John shared,

"I guess I don't really understand the way the faculty are reviewed and I haven't had much experience with learning, I guess, about that much. I know we have a review process for our doctoral program where we have an annual review on our performance and our goals and things like that, but I really don't have much knowledge about the way the faculty are reviewed. I know they have some sort of review process annually but in terms of what that consists of I can only really speculate that it's about publications and grants, things like that."

Exposure to the tenure process was mostly done by indirect means, which contributed to the participant's lack of awareness of the process. Take for example Rylan's comments about her knowledge, "I would have to say, honestly, it's fairly vague. I mean, I do see kind of what the faculty in our program are kind of going through for tenure." Jessica admits her understanding is based more on drawing conclusions from personal experiences as a student in the department, rather than any comprehensive learning opportunities. She explains,

"When somebody goes up for a promotion, they send out an email asking if people would fill out an evaluation form, which I've done. And then I know publications and - I'm trying to think of what else. I think that's pretty much all I have been aware of, that I've been told of directly. I guess I don't know anything other than that...honestly, I don't know within each of those [research, teaching, and service], how they're evaluated."

\section{Knowledge of guidelines and criteria is perpetuated by mentoring}

The participants who demonstrated a stronger self-perceived knowledge of the promotion and tenure process received mentorship in the area. That is, their doctoral advisors not only discussed the process, but also provided chances to engage in each of the areas of academic tenure. Bob shared his assessment of the tenure guidelines and criteria, but directly attributed it to his "mentor" who helped him understand the process because "my mentor talked about it." Bob said,

"They will evaluate you on your teaching ability, whether that's through course evaluations and I'm not sure how -- what else really goes into that but I would imagine your course evaluations and then kind of the distribution of how the student's do in the classes. In addition, your research or scholarly productivity, how prominent you are publishing manuscripts, seeking or paying from grant funding, and then in addition is your service to the university or other committee within the profession. That's what I feel I heard is most commonly what faculty members will be evaluated on a year to year basis and going up for a tenure position."

Annie, like Bob ascribed her knowledge of tenure to mentorship and discourse with her faculty mentor about tenure. Over time, her mentor was able to share with her information and experiences about the tenure process and the variability that can arise in institutions. She shared, "what I know is from my advisor. Just over time our conversations have made me aware of it." When directly asked about her understanding Annie said,

"Some universities are different 'cause I know that at smaller schools, they don't really value the research as much. They're really focused on the teaching, and maybe even the service. So I think it just depends on where I would go and the goals of that institution. 'Cause some of them value your research far and above more than teaching or service. So the evaluation, I think - I'm not sure if I'm answering your question. I think it's highly dependent on where you are and how you are evaluated because of the goals of the institution." When Steve was asked about how he gained his understanding of tenure, he said, "I can't say that it would be one specific thing but l'd say what really prepared me the most would be the opportunities to do more of -- a lot of the mentorship." Like many of the participants, he was generally aware of guidelines of tenure (teaching, research, service), but felt his mentor and experiences facilitated his readiness for academia.

The use of seminar courses also served as a formal means to educate and mentor the doctoral student on the tenure process. Paul said, "[we] have a weekly seminar that we do in the fall that goes through some of those aspects related to tenure and promotion." A few other students mentioned the use of a seminar course as a means to facilitate conversations about higher education and future roles they may assume with their mentors. Direct observation of faculty navigating the tenure process helped a few participants, like Mary who said "I feel like I have - I wouldn't say like a great understanding - I have a pretty good understanding because my advisor's going through it right now."

(c) The Internet Journal of Allied Health Sciences and Practice, 2017 
Nate summarized the importance of his mentor in understanding tenure and PTR guidelines. He discussed how his mentors at his institution facilitated seminar meetings as a means to spear discourse about academia and faculty roles. Nate detailed this experience,

"We've talked a little bit about the tenure process. We'll have a once a week meeting where, the entire group of doctoral students and all three of the faculty members will meet. We'll go through and talk about different topics during the meeting, and we'll share information about the different interviews that some of the students are applying for and so we get experience with that too. Then my mentor/advisor just went through his whole process of applying for tenure. So having those lab meetings, it's a really good opportunity for just discussion and learning firsthand."

\section{Research and scholarship is perceived as paramount for success}

The participants demonstrated a limited understanding of tenure guidelines and criteria, but it was evident that they believed research/scholarship to be the platform on which promotion is achieved. Many discussions focused on the ability of the faculty member to secure grant funding and be self-supporting in their research pursuits. Common responses included "I am prepared for my future research expectations," "I have the foundation for success as a researcher," and "I am very ready for the research aspect of higher education." Research appeared to be the platform for faculty evaluation for most of the participants. For example, Michael shared, "[Tenure] seems to be a lot of emphasis on publication and grant-funding, which makes sense. Obviously, if you can be somewhat self-sustaining and bring in money to support your projects, that's obviously better-reflecting." Pam, like Michael, had a very comparable perception of the tenure earning process. She shared,

"From what I understand...The tenure track positions, they're evaluating your publications, the number of grants you've brought in, the number of students you're able to support and mentor, the classes you teach, the reviews from those classes, and then professional involvement."

Elizabeth was able to articulate her thoughts on the tenure process, focusing mostly on the idea of research, with a few comments relating to service. Elizabeth shared,

"I would tell you the big things there that I would have to talk about are academic currency [in terms of tenure]. So I'm talking about publications, manuscripts, grants, scholarships, and then I know that the university would say a lot is based on some of the service that you're able to give back to the university. So things like serving on boards and taking on more of your leadership roles in those areas."

The participants strongly believed that research was a primary focus for faculty members as they work towards tenure. Many were unsure of the process, as described above, and those who believed that they had some knowledge were focused on the importance of the research component. Limited discussions were centered on teaching and services aspects, although they were mentioned sparingly.

\section{Belief that skills gained, regardless of the domain of tenure, can facilitate success in others}

Research skills were the platform for role development for the doctoral student. That is, all students were satisfied with those experiences and were able to acutely identify research as part of the tenure and promotion guidelines and criteria for success. When probed about the other areas of tenure, many, despite having insufficient experiences (such as service and administration), felt that their skills developed as a researcher could translate into successful navigation of those duties or responsibilities.

Many who felt somewhat prepared for administrative duties based this on the perception that they had the "capacity" to transfer knowledge and skills gained from other experiences to those areas where they lacked authentic experiences. Mark, a $4^{\text {th }}$ year doctoral student, believed that "various administrative tasks, I think are very easy to figure out, and if not, I can look them up." He continued that he would need more "mentorship" for the role of program director but yet he was "aware of" and "understands what is talked about in those [accreditation and annual] meetings, and situations with students and creating [clinical] agreements with students, professionalism and all those things. So that's nothing new, and I don't think that would be very difficult for me." Mark's assistantship was directly tied to research and he acknowledged a lack of formalized experiences in other areas of tenure.

Ashley, a $5^{\text {th }}$ year doctoral student described previous clinical experiences that prepared her to take on administrative roles that may accompany a future faculty position. She said,

"My clinical kind of commitments would have prepared me more for that. So just because l'm being the only one in the high school, all the admin stuff was left to myself. I think that prepared me."

Others, such as Steve, described how research experiences prepared him for administrative duties.

"As a PhD student I was managing this \$2 million project from $\mathrm{NIH}$ for my advisor, as far as administrative tasks, we do get a lot of that throughout the lab, just managing things for faculty and overseeing interns. And

(c) The Internet Journal of Allied Health Sciences and Practice, 2017 
I think, especially at this level, when you're hoping to step into more of - not a management position, but an expertise, you have to have a certain capacity for administrative tasks."

Kimberly also made the connection between the skills she received from research and administrative tasks. While she admitted she was not yet fully prepared for administrative duties that she may be charged with during her career, she thinks she will be successful due to her research experience. When asked if she had any experiences that helped with her readiness to take on administrative duties that might be associated with a future faculty position in athletic training, she stated,

"Not really, not specifically, other than just being able to manage my own projects. No, that sounds bad, but no, I mean, not that would directly transfer over to a position like that. It's pretty much just you're doing your research, and that's about it, kind of what you can - I mean, it is - it's kind of what you can - not manipulate, but what you can pull from that experience and market it to be able to transition to other experiences."

The participants felt that skills learned in one domain would simply transfer to other areas, mostly in the service and administrative aspects of tenure and promotion.

\section{DISCUSSION}

Role transition can be viewed as the culmination of the professional socialization process as the individual is able to see their training come to fruition. Specifically, doctoral students in athletic training are cultivated to assume positions within higher education; these positions likely require navigation of the tenure earning process. It has been suggested that athletic trainers in these roles, at times, struggle with gaining tenure due to the unique role they play in health care education and academia. ${ }^{3}$ It was found that like many others engaging in doctoral preparation, these students have a limited view of the complexity of the tenure process. ${ }^{20}$ The participants were very aware of the research aspect for success, but were far less articulate or cognizant about other forms used to measure achievement as a faculty member. Like Austin reported, the participants rarely discussed responsibilities beyond teaching and research, such as student advising, institutional service, and other aspects of outreach that may be necessary to demonstrate achievements for tenure. ${ }^{20}$

Faculty performance, when evaluated for tenure, falls into 3 connected, but specified areas of activity: 1) teaching, 2) research, and 3) university, professional, and public service. The participants, when asked about their knowledge and perceptions of the assessment criteria, were, at best, aware of the first two criteria. In reality, however, the participants really felt that research success navigated the tenure process. A finding that aligns with others which suggests healthcare faculty fixate on research as a means to succeed. ${ }^{21}$ Many of the participants had the mindset from a research perspective; that is they did not appear to clearly understand the impact institutional type could have on the tenure earning process. Specifically, they seemed unaware that research expectations are weighted less than teaching and service at master's or baccalaureate institutions compared to research intensive universities (i.e. doctoral granting universities), which have much larger expectations for scholarly productivity. ${ }^{14}$ Similarly to the findings of Bowman et al, the participant's perceived research to be the most critical component for career success and further believed research drove success in other areas of achievement as related to the tenets of higher education. ${ }^{8}$

The participants who demonstrated a stronger awareness of promotion guidelines and tenure seemed to receive strong mentorship. The participants' advisors recognized the need and provided diverse learning opportunities for their doctoral students. Austin found that doctoral candidates wanted more careful advising and regular supportive mentoring to aid in negotiating their experiences as they prepared for a future in academia. ${ }^{20}$ Much like the traditional athletic training student who wants an experience that is integrative, dynamic, and diverse, doctoral students also need engagement in various roles that will be expected of them in the future.22,23 These experiences include teaching (class preparation, syllabus development), research (data collection, grant writing, publication, and peer review), and service related activities (academic advising, committee work, etc.). ${ }^{7}$ Several students mentioned having formalized discourse between their mentors and advisors as a means to gain more orientation to the faculty role. Austin also discussed the critical importance of formal mentorship opportunities for doctoral student socialization and role inductance to academia. ${ }^{20}$

Many scholars suggest newly hooded faculty are blind to the burden of the administrative roles associated with academia, that often increase with roles such as athletic training program director or clinical coordinator. 2,3 Interestingly, the participants were not daunted by these potential expectations, as they felt the skills they possessed and experiences they had in other areas were enough to prepare them to succeed. The lack of exposure to these specific tasks could be a result of the participants' mentors. Many identified their mentors as their research advisors; individual's likely void of administrative duties such as the program director or clinical coordinator. ${ }^{9}$ Thus, the focus of their mentoring may not be on those skill sets. Also, a majority of the participants were awarded doctor of philosophy degrees, not doctorates of education, which would suggest a focus more on teaching and pedagogy in addition to research. ${ }^{24,25}$ The differences between a Doctor of Philosophy and Doctor of Education may be indistinguishable, however a Doctor of Philosophy is designated for individuals who have a clear interest in research.

(c) The Internet Journal of Allied Health Sciences and Practice, 2017 


\section{LIMITATIONS AND FUTURE DIRECTIONS}

Data are presented from the perspective of doctoral students as they are becoming socialized into their future roles. Tenure expectations will vary based upon the future faculty members' final selection of institution for employment, thus full understanding and comprehension of those expectations may change. In the future, there should be follow-up with the participants once they have begun the process of earning tenure to gain more data on their experiences once transitioned into the role. This study was exploratory in nature, and therefore included students in the infancy of their doctoral education, thus it is possible they had yet to fully be socialized into the role of the faculty member in higher education. This could influence their knowledge and perceptions of the tenure process. Longitudinal data in the future may help fully understanding doctoral students' experiences as they learn the roles and responsibilities of a faculty member. As their experiences amass, they are more likely to gain a more robust understanding of role expectations.

\section{CONCLUSIONS}

Institutional tenure expectations will likely be reviewed with faculty members once they gain employment. However, it is also important that they receive a general overview of the general expectations prior to their full-time employment. In fact, the doctoral education experience is built on the premise of preparing students for their future professorial role. The participants demonstrated a partial understanding of the tenure expectations they will likely face as they transition into higher education. All participants noted the expectations they will likely have as researchers and educators, but many had incomplete understand regarding service and administration. However, mentoring did seem to positively influence our participants' knowledge regarding the tenure process. Those faculty members who are mentoring doctoral candidates are encouraged to provide diverse experiences that include all the aspects of a role in academia.

\section{REFERENCES}

1. Patton MQ. Enhancing the quality and credibility of qualitative analysis. Health Serv Res.1999;34(5 Pt 2):1189-208. [PMID: 10591279]

2. Starkey C, Ingersoll CD. Scholarly productivity of athletic training faculty members. J Athl Train. 2001;36(2):156-9. [PMID:

1. 12937457]

2. Dewald L, Walsh K. Tenure track athletic training educators: are they being set up to fail? Athl Train Educ J. 2009;4:144-9.

3. Menges RJ, Schuster JH. Faculty in New Jobs: A guide to settling in, becoming established, and building institutional support. San Francisco, CA: Jossey-Bass Inc.,U.S.; April 30, 1999.

4. Commission on Accreditation of Athletic Training Education. The professional degree. http://caate.net/theprofessional-degree. Accessed April 4, 2017.

5. Payne EK, Berry DC. From graduate student to professor: reflection on the transition and tips for those who follow. Athl Train Educ J. 2014; 9(2):87-93.

6. Bowman TG, Mazerolle SM, Klossner JK. The Professional Socialization of Doctoral Students Seeking Careers in Athletic Training. Oral Presentation at: National Athletic Trainers' Association Annual Meeting and Clinical Symposia. St. Louis, MO June 24, 2015.

7. Bowman TG, Klossner JC, Mazerolle SM. The athletic training doctoral experience: Facilitators and barriers to anticipatory faculty socialization. Athl Train Educ J. In Review.

8. Mazerolle SM, Bowman TG, Klossner JC. An analysis of doctoral students' perceptions of mentorship during their doctoral studies. Athl Train Educ J. 2015;10(3):227-35. doi: 10.4085/1003227.

9. Holcomb JD, Selker LG, Roush RE. Scholarly productivity: a regional study of physical therapy faculty in schools of allied health. Phys Ther. 1990;70(2):118-24. [PMID: 2296611]

10. Zyzanski SJ, Williams RL, Flocke SA, Acheson LS, Kelly RB. Academic achievement of successful candidates for tenure and promotion to associate professor. Fam Med.1996;28(5):358-63. [PMID: 8735064]

11. Pitney WA. Professional socialization of certified athletic trainers in high school settings: a grounded theory investigation. J Athl Train. 2002;37:286-92. [PMID:12937587]

12. Pitney WA, Ilsley P, Rintala J. The professional socialization of certified athletic trainers in the National Collegiate Athletic Association division I context. J Athl Train. 2002;37(1):63-70. [PMID:12937446]

13. The Carnegie Classification of Institutions of Higher Education. About Carnegie Classification. http://carnegieclassifications.iu.edu. Accessed April 4, 2017.

14. Creswell JW, Plano-Clark VL. Designing and Conducting Mixed Methods Research. Thousand Oaks, CA: Sage Publications; 2007.

15. Pitney WA, Parker J. Qualitative Research in Physical Activity and the Health Professions. Champaign, IL: Human Kinetics; 2009.

(c) The Internet Journal of Allied Health Sciences and Practice, 2017 
16. The Carnegie Classification of Institutions of Higher Education. http://carnegieclassifications.iu.edu/classification_descriptions/basic.php. Accessed April 4, 2017.

17. Klossner $J$. The role of legitimation in the professional socialization of second-year undergraduate athletic training students. J Athl Train. 2008;43:379-85. [PMID: 18668171]

18. Thomas D. A general inductive approach for qualitative data analysis. Amer J Eval. 2006;27:237-46.

19. Austin AE. Preparing the next generation of faculty: Graduate school as socialization to the academic career. J High Educ. 2002;71(1):94-122.

20. Epple Calvert ML, Vaughn CA, Sullivan CA, Garn G. Knowledge and perceptions of tenure guidelines and criteria among allied health faculty: case study. J Allied Health. 2007;36(2):e142-59. [PMID:19759988]

21. Benes SS, Mazerolle SM. Factors influencing athletic training students' perceptions of the athletic training profession and career choice. Athl Train Educ J. 2014:9(3):104-12.

22. Mazerolle SM, Benes SS. Factors influencing senior athletic training students preparedness to enter the workforce. Athl Train Educ J. 2014;9(1):5-11.

23. What is the difference between $\mathrm{EdD}$ and $\mathrm{PhD}$ in education? http://www.educationdegree.com/articles/edd-and-phddifferences. Accessed April 4, 2017.

24. EdD vs. PhD Degrees. https://teach.com/how-to-become-a-teacher/get-educated/doctorate-in-education-edd/edd-vsphd-degrees. Accessed April 4, 2017. 